\title{
Bedah rehabilitasi rectovaginal fistula pada kuda
}

\author{
Amrozi $^{1 * *}$, R. Harry Soehartono ${ }^{1}$, Erly R. Adistya ${ }^{2}$, Iga Mahardi ${ }^{3}$, \\ Hidayati Mukarromah ${ }^{3}$, M. Ibnu Satria ${ }^{3}$ \\ ${ }^{1}$ Departemen Klinik Reproduksi dan Patologi, Fakultas Kedokteran Hewan, Institut Pertanian Bogor, Bogor \\ ${ }^{2}$ Rumah Sakit Hewan Pendidikan, Fakultas Kedokteran Hewan, Institut Pertanian Bogor, Bogor \\ ${ }^{3}$ Dr Am Veterinary Services, Jl. Ketimun C93, Sinarsari, Dramaga, Bogor
}

\begin{abstract}
ABSTRAK: Rectovaginal fistula (RVF) merupakan fistula yang terbentuk antara rektum dan vagina sehingga feses masuk ke vagina dan menyebabkan endometritis. Seekor kuda primipara umur 6 tahun mengalami RVF. Rehabilitasi RVF pada kuda ini dilakukan dengan tindakan bedah penjahitan fistula dengan anestesi general. Sedasi menggunakan xylazine, induksi dengan ketamine serta maintenance dengan inhalasi isofluran. Luka baru dibuat pada tepi fistula dan penjahitan dilakukan sesuai dengan arah fistula dengan jahitan sederhana. Terapi pascabedah yaitu pemberian antibiotik selama 10 hari, antiinflamasi 5 hari dan analgesik 3 hari. Diet pascabedah dilakukan dengan memberikan pakan rumput segar. Persembuhan jaringan 10 hari pascabedah ditandai dengan terbentuk jaringan baru dan tidak ada feses yang masuk ke dalam vagina.
\end{abstract}

\section{Kata kunci:}

rectovaginal fistula, kuda, rektum, vagina

\section{- PENDAHULUAN}

Rectovaginal Fistula (RVF) merupakan fistula yang terbentuk antara rektum dan vagina sehingga menyebabkan feses masuk ke dalam vagina dan menyebabkan infeksi kronis (Marc et al. 1993). Kasus RVF sering terjadi pada kuda primipara (Mehrjerdi et al. 2010) dan dapat menyebabkan vaginitis, servisitis serta endometritis sehingga meningkatkan infertilitas (Jalim \& McKinnon 2010). Fistula ini terjadi saat kuda mengalami distokia dimana hidung atau kaki anak kuda (dapat keduanya) akan terlihat keluar dari rektum. Kasus RVF juga dapat terjadi akibat kegagalan dari tindakan bedah kasus third degree perineal laceration. Tindakan bedah dapat dilakukan setelah 3-6 jam pascamelahirkan, karena akan diikuti oleh edema jaringan, inflamasi, perdarahan, kontaminasi dari feses dan nekrosis jaringan (Schonfelder \& Sobiraj 2004). Tulisan ini melaporkan penanganan kasus RVF pada kuda.

\section{- KASUS}

Kuda crossbreed lokal dan thoroughbreed, umur 6 tahun datang ke Unit Rehabilitasi Reproduksi, Fakultas Kedokteran Hewan, Institut Pertanian Bogor dengan keluhan feses keluar dari vagina saat defekasi maupun urinasi serta cairan putih berbau busuk dari vagina. Pemeriksaan fisik dilakukan dan ditemukan fistula antara rektum dan vagina dengan diameter sekitar $7 \mathrm{~cm}$, jaringan disekitar fistula sudah menjadi jaringan ikat. Hasil ultrasonografi menunjukkan endometritis kronis berupa akumulasi cairan nanah didalam uterus. Tindakan yang dilakukan adalah tindakan bedah penjahitan fistula.

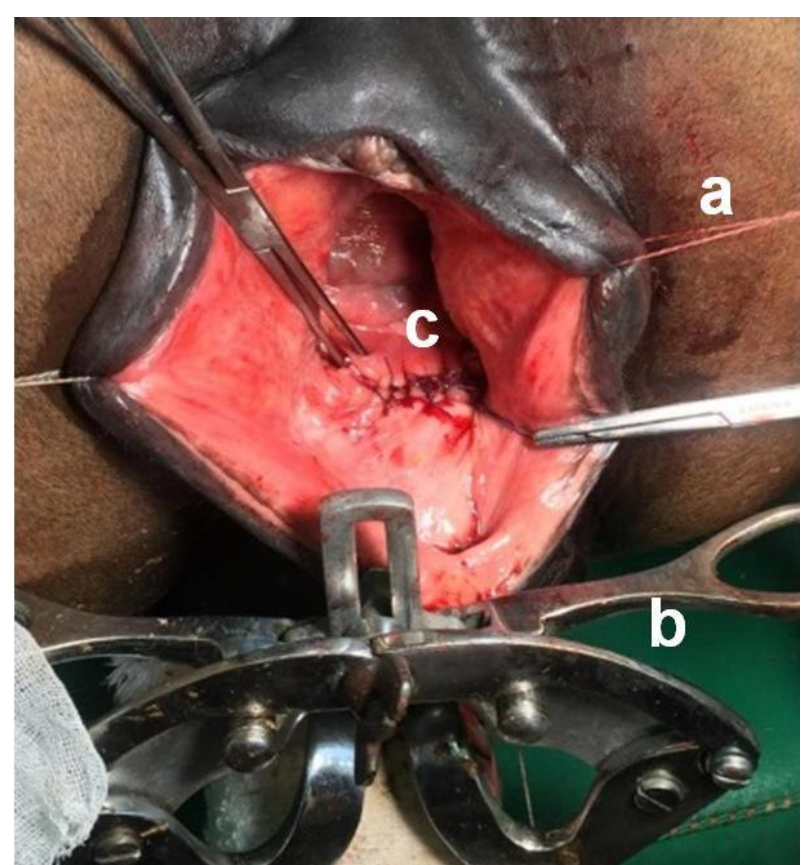

Gambar 1 Tindakan bedah Rectovaginal fistula. (a) benang yang dipasangkan pada vulva, (b) vaginoskop yang dipasangkan pada rektum, dan (c) jahitan fistula melintang terhadap rektum.

Persiapan sebelum tindakan bedah adalah pengaturan diet untuk mengatur konsistensi feses kuda agar tidak terlalu

Diterima: 05-10-2019 | Direvisi: 30-10-2019 | Disetujui: 02-11-2019 (C) 2019 CC-BY-SA. Ini adalah artikel Open Access yang didistribusikan berdasarkan ketentuan dari Creative Commons Attribution ShareAlike 4.0 International License (https://creativecommons.org/licenses/by-sa/4.0/). 
encer. Feses yang encer akan merembes ke dalam vagina melalui jahitan sehingga dapat mengganggu proses persembuhan luka. Kuda tidak diberikan konsentrat selama 5 hari sebelum bedah. Kuda hanya diberikan rumput pada setiap jadwal makannya. Kuda puasa total dari rumput dan konsentrat selama 24 jam sebelum bedah dan hanya disediakan minum.

Posisi kuda selama bedah adalah dorsal rekumbensi dengan pemberian anatesi general kombinasi xylazine 1,1 $\mathrm{mg} / \mathrm{kg}$ bobot badan dan ketamine $2,2 \mathrm{mg} / \mathrm{kg}$ bobot badan diberikan secara i.v. serta isofluran untuk maintenance selama tindakan bedah berlangsung. Vaginoskop ditempatkan pada rektum sehingga memudahkan pencapaian posisi fistula. Penjahitan fistula dilakukan dari vagina. Labia kiri dan kanan dipasangkan benang dan ditarik ke lateral sehingga ruang penjahitan menjadi lebih luas. Jaringan ikat yang terdapat pada fistula di gunting untuk membentuk luka baru. Mukosa vagina ditarik dari arah kranial ke kaudal kearah spinkter ani sehingga jahitan mengarah melintang terhadap rektum (Gambar 1). Jahitan sederhana dilakukan menggunakan benang polyglycolic acid 4-0 pada fistula. Mukosa vagina dan rektum dijahit secara bersamaan sehingga hanya terdapat 1 lapis jahitan yang mengarah ke vagina. Metode ini dilakukan untuk mengurangi tekanan saat kuda defekasi.

Terapi pasca bedah yang diberikan yaitu pemberian antibiotik gentamisin $6,6 \mathrm{mg} / \mathrm{kg}$ bobot badan selama 10 hari, antiinflamasi deksametason $2,5 \mathrm{mg} / \mathrm{kg}$ bobot badan selama 5 hari dan analgesik penilbutazon $5 \mathrm{mg} / \mathrm{kg}$ bobot badan selama 3 hari. Kuda hanya diberikan pakan rumput segar selama 10 hari pasca bedah. Bekas jahitan sudah tampak rata setelah 10 hari pascapenjahitan. Luka tertutup rapat dan tidak ada celah yang tampak. Feses tidak ditemukan masuk ke dalam vagina saat defekasi.

\section{- HASIL DAN PEMBAHASAN}

Keberhasilan tindakan bedah RVF dipengaruhi oleh kekuatan jaringan sekitar fistula, edema jaringan sekitar dan kontaminasi feses (Schonfelder \& Sobiraj 2004, Hospes \& Bleul 2007, Mehrjerdi et al. 2010). Puasa sehari sebelum operasi pada kasus ini dilakukan untuk menghilangkan kontaminasi feses selama proses pembedahan. Diet pakan berupa rumput segar dilakukan untuk menghindari terjadinya kolik. Selain itu, feses menjadi lebih lembut dan berbentuk bulat normal sehingga diharapan tidak terjadi penetrasi feses ke celah luka jahitan. Tingkat keberhasilan dari tindakan bedah RVF cukup tinggi dan sekitar $87 \%$ kuda dapat bunting kembali pasca RVF (Mehrjerdi et al. 2010). Akan tetapi, kemungkinan terjadinya RVF kembali setelah melahirkan masih dapat terjadi meskipun dengan potensi keterulangan sangat rendah (Kasikci et al. 2005).

\section{- SIMPULAN}

Rectovaginal fistula pada kuda dapat direhabilitasi dengan tindakan pembedahan menggunakan metode jahitan sederhana dan pemberian diet pakan rumput segar agar feses menjadi lebih lembut dan menghindari kolik.

\section{- INFORMASI PENULIS}

Penulis untuk Korespondensi

*A: amrozi217@gmail.com

Laboratorium Kebidanan dan Kemajiran, Fakultas Kedokteran

Hewan, Institut Pertanian Bogor, Bogor, INDONESIA

\section{- PUSTAKA ACUAN}

Hospes R, Bleul U. 2007. The effect ofextended preoperative fasting in mares undergoing surgery of the perineal region. Journal of Equine Veterinary Science. 27(12): 542-545.

Jalim SL, McKinnon AO. 2010. Surgical correction of rectovaginal fistula in mares and subsequent fer tility. Australian Veterinary Journal. 88(6): 211-214.

Kasikci G, Horoz H, Alkan S, Duzgun O, Aktas M. 2005. A modified surgical technique for repairing third-degree perineal lacerations in mares. Acta Veterinaria Hungarica. 53(2): 257-264.

Marc RD, Donald RT, Christopher BL. 1993. Surgical repair of rectovaginal fistulae in mares: Twelve cases (1983-1991). The Canadian Veterinary Journal. 34(4): 226-231.

Mehrjerdi HK, Sardari K, Emam MR. 2010. Surgical repair of thirddegree perineal laceration by Goetz technique in the mare: 7 cases (2000-2005). Iranian Journal of Veterinary Research 11(2):184-188.

Schonfelder AM, Sobiraj A. 2004. A vaginal mucosal pedicle flap. Veterinary Surgery. 33(5): 517-520. 